\title{
Interaction between Ti-48Al Alloy and Coating Materials during the Solidification Process
}

\author{
Sui Yanwei, Feng Kun, Cheng Cheng, Qi Jiqiu, He Yezeng, Wei Fuxiang, \\ Meng Qingkun, Sun Zhi, Shen Chengjin
}

China University of Mining and Technology, Xuzhou 221116, China

\begin{abstract}
The effect of coating materials on the metal-coating interface, alloy chemical composition and microstructure was evaluated by scanning electron microscopy, energy dispersive spectroscopy and X-ray diffraction analysis. Microhardness variation from the surface to the inside of the samples was compared. The results indicate that inordinate interaction occurs at the interface between the coating and the melt. The crucible layer is found to suffer chemical dissolution and some physical erosion by the molten alloy and the extent of that dissolution depend partly on the coating material. Additionally, the thermodynamics of the TiAl/Oxide reactions have been studied, and the main mechanism responsible for the contamination of the directional solidification samples is diffusion controlled dissolution of the coatings in the melt which increases the oxygen content in the matrix.
\end{abstract}

Key words: directional solidification; interfacial reactions; TiAl alloys; protective coatings

TiAl-based alloys exhibit numerous outstanding properties, such as low density, high melting temperature, good elevated-temperature strength and modulus retention, high resistance to oxidation and excellent creep properties $^{[1,2]}$. Such characteristics make them suitable structural materials for various applications in the gas turbine and automotive industry ${ }^{[3,4]}$. However, the production of titanium castings is not an easy task, mainly due to the high reactivity of the alloys, high fusion point, large heat capacity and low thermal conductivity ${ }^{[5-7]}$ Even more critically, the resulting TiAl alloy castings could have all kinds of casting defects, such as casting surface contamination layer, porosity, pores and shrinkage. These defects directly affect the quality and performance of the castings, and ultimately lead to increased costs. Therefore, it is necessary to investigate the interactions between refractory materials and TiAl alloy melts, as well as to select the suitable refractory materials as crucibles or molds for melting or for casting the alloy.
To date, many researchers have investigated the interactions between TiAl alloy melts and refractory materials, including borides, carbides, sulfides, nitrides and oxides. Specifically, Virieux et al. studied the behavior of two Ni-based alloys, A and B, which were compared on the basis of their contact angles on four different oxide ceramics, namely amorphous silica, $\mathrm{MgO}_{2}$-stabilized zirconia, hafnium oxide and alumina ${ }^{[8]}$. Koltsov et al. determined the factors governing the growth kinetics in metal/non-oxide ceramic systems in which strong reactivity is often observed ${ }^{[9]}$. In addition, Fu Binguo et al. melted Ti-1100 alloys in a controlled atmospheric induction furnace equipped with a $\mathrm{CaO}$ crucible and found that the oxide family of materials receives the most attention ${ }^{[10]}$. Accordingly, it is instructive to theoretically predict the thermodynamic stability of oxides and to investigate the interactions between TiAl alloy melts and oxides ${ }^{[11,12]}$. In the present study, Ti-48Al alloys were melted in a vacuum induction melting (VIM) furnace equipped with a U-shaped yttria

Received date: December 14, 2015

Foundation item: National Natural Science Foundation of China (51304198); Natural Science Foundation of Jiangsu Province (2013106, 20141134, 2014028-08) Corresponding author: Qi Jiqiu, Ph. D., Lecturer, School of Material Science and Engineering, China University of Mining and Technology, Xuzhou 221116, P. R. China, E-mail: wuyandushang163@163.com 
crucible, and then the samples were obtained by the directional solidification process. The interactions were evaluated by energy dispersive spectrometry (EDS), scanning electron microscopy (SEM), X-ray diffraction (XRD) and the hardness tester. The aim of this paper is to study the mechanisms of metal-coating interactions and to discuss the protection effectiveness of the coating materials.

\section{Experiment}

\subsection{Raw materials}

Ti-48Al binary alloys were selected for melting, prepared from the commercially titanium sponge $(99.76 \%)$ and high purity Al ingot $(99.99 \%)$. Special care was taken to clean the raw materials, using an acetone solution in an ultrasonic bath. After cleaning, they were dried at $150{ }^{\circ} \mathrm{C}$ for $120 \mathrm{~min}$ and melted in a VIM furnace equipped with a U-shaped yttria crucible. Additionally, the button was melted and turned five times to promote homogeneity. Before heating the graphite molds, they were preheated at $200{ }^{\circ} \mathrm{C}$ for $1 \mathrm{~h}$. In order to prepare samples that would fit into the molds, the arc-melted button was cut into master alloy bars with a diameter of about $6 \mathrm{~mm}$ using electrical discharge machining (EDM). All raw materials in granular $(44 \mu \mathrm{m})$ form were placed in the furnace at the same time by optimizing the placement, so that full advantage of the exothermic reaction can be taken. Eventually, the yttria crucibles containing the solidified metal were removed from the furnace at a temperature of about $50{ }^{\circ} \mathrm{C}$. The nominal composition of the master ingot was Ti-48Al-7Nb-2.5V-1Cr.

In this study, low cost and good thermal shock resistance aluminum molds with outer diameter of $8 \mathrm{~mm}$, inner diameter of $6 \mathrm{~mm}$, length of $100 \mathrm{~mm}$, wall thickness of 0.5 $\mathrm{mm}$ and different inner coatings were used in directional solidification to produce TiAl alloys. The coatings were made from each of the four aforementioned oxide ceramic slurry materials without alkali metal binders/additives. The slurry consisted of pure ceramic powder (99.9\%), $\mathrm{TiO}_{2}$ powder $(99.98 \%)$, latex, yttrium sol and deionized water. The $\mathrm{pH}$ value of the prepared coating material should vary between 9 and 10, and the viscosity between 0.45 and 0.55 $\mathrm{Pa} \cdot \mathrm{s}$.

\subsection{Directional solidification operation}

The directional solidification was performed using a laboratory-scale Bridgman furnace (liquid metal cooling technology). Before each experiment, the furnace chamber was evacuated down to $5 \times 10^{-3} \mathrm{~Pa}$ and then backfilled with high purity argon up to $0.5 \mathrm{~Pa}$, which was repeated three times in order to reduce the oxygen content to a minimum level and to prevent the evaporation of alloy components. The temperature of the furnace was slowly raised at a rate of $1 \mathrm{~K} / \mathrm{min}$ before reaching $1400{ }^{\circ} \mathrm{C}$, in order to avoid ceramic cracking. Afterwards, the heating rate was increased to reach the desired temperature as fast as possible, and then the melt inside the mold was stabilized at $1600{ }^{\circ} \mathrm{C}$ for $8 \mathrm{~min}$ in the furnace and allowed to undergo directional solidification at a withdrawal rate of $6 \mathrm{~mm} / \mathrm{min}$ and a temperature gradient of $10^{3} \sim 10^{4} \mathrm{~K} / \mathrm{m}$ until the entire mold had fallen into the Ga-In-Sn alloy solution. Finally, the mold containing the directional solidification (DS) ingot was removed from the furnace at about $50{ }^{\circ} \mathrm{C}$.

\subsection{Inspection of the melted samples}

Samples for characterization were collected from the middle of the cast cylinders by sectioning them at $50 \%$ of their height. The metal-coating interface and chemical composition were evaluated by SEM (FEI Quanta TM 250) and quantitative EDS analysis (Quantax400-10). Phase identification of the compounds was accomplished by XRD (D8Adance) at constant voltage $(40 \mathrm{kV})$ and current (30 $\mathrm{mA}$ ) with $\mathrm{Cu} \mathrm{K} \alpha$ radiation. A HVS-50 hardness tester with $5 \mathrm{~N}$ load for $15 \mathrm{~s}$ was used to measure the microhardness of the melted samples from the surface to the inside of the melt at $5 \mu \mathrm{m}$ interval, three times at every point.

\section{Results}

\subsection{Metal-coating interface}

The microstructures of the metal-coating interface of different samples are shown in Fig.1, where he obvious layers of oxides on the sample surface and few inclusions dispersed in the matrix can be observed. Varying degrees of interfacial reactions occurs between the DS Ti-48Al alloy and aluminum mold with different protective coatings. The thickest reaction layer of interface obtained indicates that the most serious interface reaction occurred between the alloy and $\mathrm{ZrO}_{2}$, as shown in Fig.1b. In comparison, the interface reaction layer is relatively thinner between the alloy and $\mathrm{Al}_{2} \mathrm{O}_{3}$ with a half value between that of the alloy and $\mathrm{ZrO}_{2}$. According to the SEM micrographs, the thinnest layer is obtained by the interface between the alloy and $\mathrm{Y}_{2} \mathrm{O}_{3}$. Moreover, as can be surmised from Fig.1a, the melt appears to be polluted by dissolution and diffusion of the $\mathrm{Y}_{2} \mathrm{O}_{3}$ coating. A completely clear and porous reaction layer accompanied by slight adhering sands, in which the products have different sizes and shapes, also exhibit dissimilar morphologies in different locations, as shown in Fig.1b. The $\mathrm{ZrO}_{2}$ coating is completely converted into black phases with metallic luster and bonded together with the alloy after the directional solidification experiments. This layer with adhesive materials could not be cleared, which made an uneven surface. At the same time, it avoids direct contact with the coating materials which is similar to what was reported in the paper by Luo Wenzhong et al. ${ }^{[13]}$ In an earlier study he also suggested that the organization was formed by $\mathrm{ZrO}_{2}$ and alloys, which impregnated with each other ${ }^{[14]}$. 

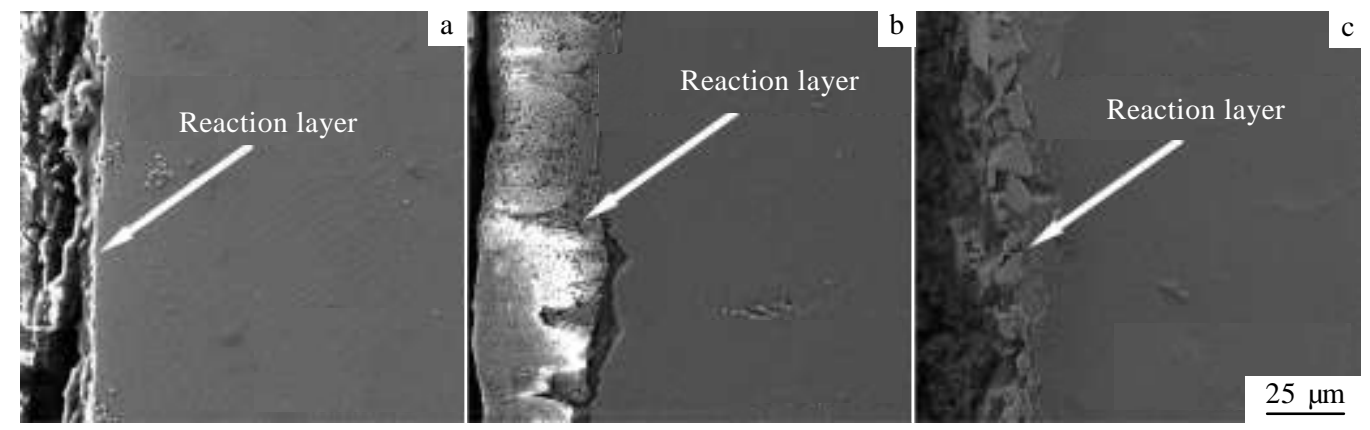

Fig.1 Interface morphologies of castings with different coatings: (a) $\mathrm{Y}_{2} \mathrm{O}_{3}$, (b) $\mathrm{ZrO}_{2}$, and (c) $\mathrm{Al}_{2} \mathrm{O}_{3}$

The XRD patterns of the interfaces between the different coatings and the melt are shown in Fig.2. Strong peaks of $\gamma(\mathrm{TiAl})$ with $\alpha_{2}\left(\mathrm{Ti}_{3} \mathrm{Al}\right)$ and weak peaks of $\mathrm{TiO}_{2}, \mathrm{ZrO}_{2}, \mathrm{Y}_{2} \mathrm{O}_{3}$ and $\mathrm{Al}_{2} \mathrm{O}_{3}$ can be discerned, but no peaks of the pure substances like $\mathrm{Y}, \mathrm{Zr}$ and $\mathrm{Al}$ are found in the pattern. It indicates the absolute diffusion of these elements in the melt and the formation of a layer by interfacial reaction. In addition, $\mathrm{TiO}_{2}, \mathrm{Y}_{2} \mathrm{O}_{3}$ and $\mathrm{Al}_{2} \mathrm{O}_{3}$, which exist in the coating, appear at the interface of castings. Accordingly, it reveals that serious shedding and peeling occurrs in the coating material during the directional solidification process. Furthermore, the diffusion of debris under the concentration gradient into the melt leads to the formation of the interfacial layer.

\subsection{Chemical composition}

Elements of the cross-sectional EDS depth profiles of the different coated Ti-48Al alloys are shown in Fig.3. These results reveal that every sample has a little contamination and the variety of enrichment profiles of the elements in Fig. 3 is found to delineate two distinct regions and the coating-melt interface. In both regions, the enrichment of elements remains stable, but it varies extensively at the interface. According to the EDS elements distribution

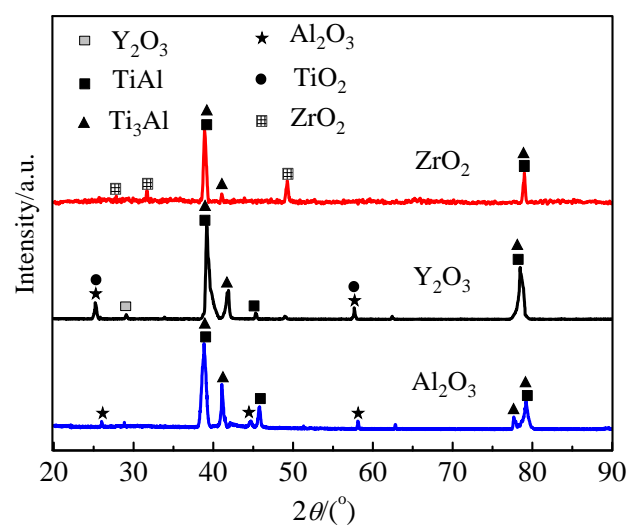

Fig.2 XRD patterns of the interfaces between different coatings and melt across the interface, the elements in both the coatings and the melt have diffused and a series of phases separate in the solidification process, which is supported by the results shown in Fig.2. Besides Y, Zr, Al, etc., O can be regarded as the key factor responsible for the interfacial interaction, as
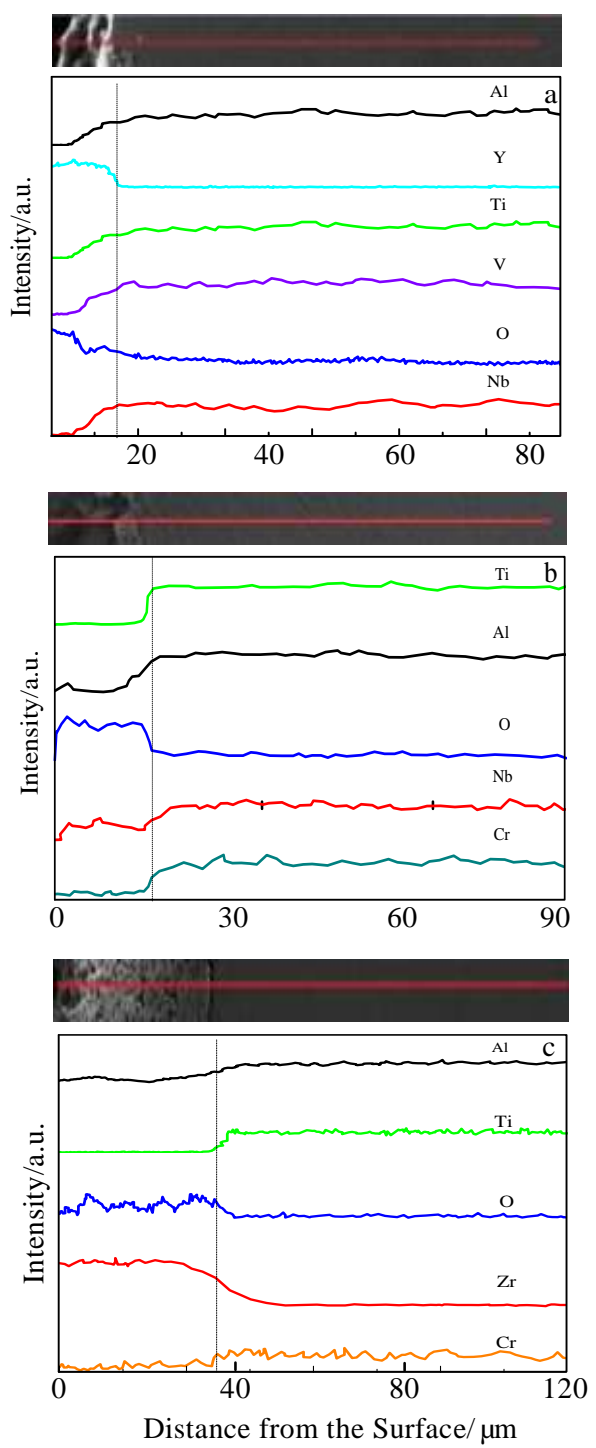

Fig.3 EDS elements depth profiles of castings with different coatings: (a) $\mathrm{Y}_{2} \mathrm{O}_{3}$, (b) $\mathrm{Al}_{2} \mathrm{O}_{3}$, and (c) $\mathrm{ZrO}_{2}$ 


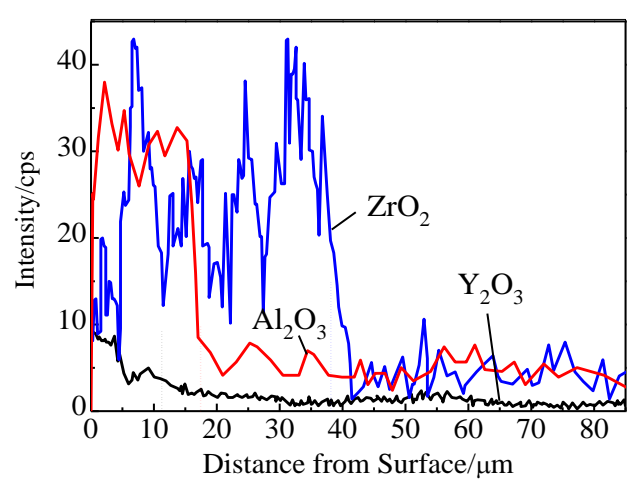

Fig.4 Oxygen enrichment of samples with different coatings

suggested by the oxygen enrichment of the samples with different coatings, presented in Fig.4, where the dotted lines represent the interface. The $\mathrm{O}$ concentration is higher at the surface, and it decreases towards the inside of the samples until reaching the average values. The distance from the surface where the $\mathrm{O}$ concentration becomes constant $(\mathrm{O}$ diffusion depth) should have some important relationship with the coating ceramics (about 12, 18 and $38 \mu \mathrm{m}$ for $\mathrm{Y}_{2} \mathrm{O}_{3}$, $\mathrm{Al}_{2} \mathrm{O}_{3}$ and $\mathrm{ZrO}_{2}$, respectively).

\subsection{Microhardness}

The results of the Vickers microhardness test, for different coating ceramic materials, show variations at different distances from the sample surface, presented in Fig.5. It is noteworthy that the measurements of microhardness were performed only in the fully lamellar regions without inclusions. The microhardness profiles reveal two distinct regions (Fig.5). In the first region, for both coatings, the microhardness decreases with the increasing distance from the surface until a certain distance from the surface is reached. For example, for the samples melted in $\mathrm{Y}_{2} \mathrm{O}_{3}, \mathrm{Al}_{2} \mathrm{O}_{3}$ and $\mathrm{ZrO}_{2}$, the distance is about 12 , 18 and $38 \mu \mathrm{m}$, respectively. In the second region, the microhardness $\mathrm{HV}$ is characterized by a low and constant value (about $3000 \mathrm{MPa}$ in every sample), which is the same magnitude as those in bulk.

\section{Discussion}

\subsection{Thermodynamic analysis}

The thickness of the reaction layer of the samples with different coatings was calculated with the values from the results in Fig.1, Fig.3 and Fig.5. These results show that the reaction layer thickness is different for different samples. Obviously, the thickness of the sample with $\mathrm{ZrO}_{2}$ coating is double that of $\mathrm{Al}_{2} \mathrm{O}_{3}$.

It can be deduced that the thickness of different samples has a strong link with the stability of the ceramic material at high temperature. Additionally, the thermodynamic stability of the oxides in contact with molten TiAl alloy was

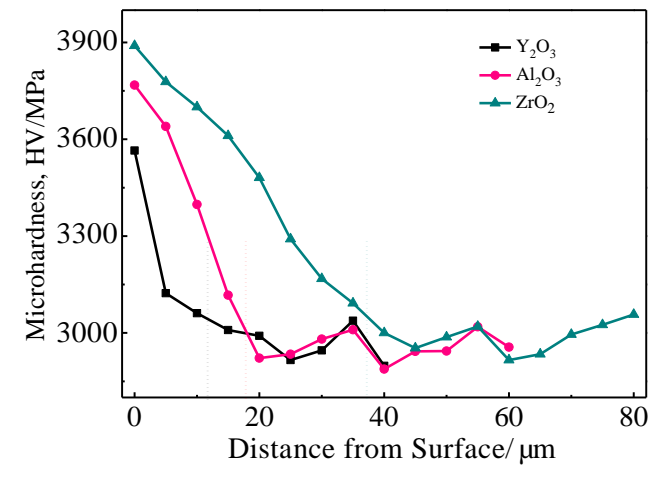

Fig.5 Microhardness profiles in samples from surface for different coatings

investigated according to the Gibbs free energy change of the dissolution reaction using Eqs.(1), (2) and (3) ${ }^{[15,16]}$.

$$
\begin{gathered}
\Delta G_{\mathrm{Y}_{2} \mathrm{O}_{3}}^{\Theta}=-1897.862+281.96 \times 10^{-3} T \\
\Delta G_{\mathrm{Al}_{2} \mathrm{O}_{3}}^{\Theta}=-1682.927+323.24 \times 10^{-3} T \\
\Delta G_{\mathrm{ZrO}_{2}}^{\Theta}=1082.520+182.96 \times 10^{-3} T
\end{gathered}
$$

In this study the melting temperature was selected as $1873.15 \mathrm{~K}\left(1600{ }^{\circ} \mathrm{C}\right)$, and the Gibbs free energy changes of the different coating oxides at $1600{ }^{\circ} \mathrm{C}$ are shown in Table 1 .

According to the results presented in Table 1, the $\mathrm{Y}_{2} \mathrm{O}_{3}$ coating oxide exhibits the least interactional Gibbs free energy. This implies that it is the hardest to dissolve at constant high temperature, and it has the best stability at high temperature of the three oxides. The results in Table 1 also reveal that an intense interaction occurs between the $\mathrm{ZrO}_{2}$ coating and the cast alloy. Accordingly, $\mathrm{Y}_{2} \mathrm{O}_{3}$ is thermodynamically much more stable than $\mathrm{Al}_{2} \mathrm{O}_{3}$ and $\mathrm{ZrO}_{2}$, so no reaction of the oxide with the cast alloy should be expected. In addition, the standard free energy diagrams do not give the correct picture of the reactivity of the oxides with the liquid metal, and it is possible that the dissolution of the oxide by the liquid metal is the reason for alloy contamination. Due to the major inflated coefficient between the volume and temperature of $\mathrm{ZrO}_{2}$, the interfacial distortion and porous surface occur with the decreasing temperature in the casting process. As a result, there is a continuous layer of $\mathrm{ZrO}_{2}$ clearly seen at the sample surface with an average thickness of about $38 \mu \mathrm{m}$ (Fig.1c). The inclusions of deeper color phases, which separate the bonding layer and basic alloy and roughens the casting surface, can be noticed in the region between the bonding layer and the melt. The observed morphology is formed by erosion from the interaction between the bonding layer and the basic alloy with each other. The interaction between the TiAl alloy and the $\mathrm{ZrO}_{2}$ coating occurs only at the surface 
Table 1 Gibbs free energy change of different coating oxides at $1600{ }^{\circ} \mathrm{C}$

\begin{tabular}{cccc}
\hline Coating oxide & $\mathrm{Al}_{2} \mathrm{O}_{3}$ & $\mathrm{ZrO}_{2}$ & $\mathrm{Y}_{2} \mathrm{O}_{3}$ \\
\hline$\Delta G^{\Theta} / \mathrm{kJ} \cdot \mathrm{mol}^{-1}$ & -1077.45 & -739.808 & -1369.71 \\
\hline
\end{tabular}

of casting, and no inclusions are found in the alloy, as can be seen in Fig.1c. Moreover, the porous contamination layer suggests that it has a unique mechanism. According to the results by Cancarevic et al., the reduced atmosphere formed by the melting of graphite body at high temperature would absorb the [O] from $\mathrm{ZrO}_{2}$, resulting in a series of crystal defects, which disperse into the matrix and form black $\mathrm{ZrO}_{2}{ }^{[17]}$. Thus, this is the reason why the thickness of the sample with $\mathrm{ZrO}_{2}$ coating is double that of $\mathrm{Al}_{2} \mathrm{O}_{3}$ and $\mathrm{Y}_{2} \mathrm{O}_{3}$.

\subsection{Interaction mechanisms}

In the search for suitable mold materials, the oxide family of materials has received the most attention. The free energy diagram for oxides is useful for comparison of the relative stability of oxides, which was performed using Eqs.(1), (2) and (3). According to the comparison, no reaction between the mold and the oxide should be expected. However, the elements in the cast samples (Fig.3 and Fig.4) reveal that some sort interaction occurs in the solidification process. Therefore, they are not only related to thermodynamic stability of the oxides but also influenced by the solubility of the oxides in the TiAl alloy.

One possible mode of the interaction of the TiAl alloy and the oxides would be dissolution of elements like $\mathrm{Y}, \mathrm{Zr}$, $\mathrm{Al}$ and $\mathrm{O}$ in the melt by the reaction of $\mathrm{Y}_{2} \mathrm{O}_{3}$, for example in reaction (4):

$$
\mathrm{Y}_{2} \mathrm{O}_{3}(\mathrm{~s})=2 \mathrm{Y}(\text { in TiAl melt })+3 \mathrm{O} \text { (in TiAl melt) }
$$

For which the equilibrium constant is:

$K=\left[\mathrm{Y}_{\text {inTiAl }} \text { at } \%\right]^{2} \cdot\left[\mathrm{O}_{\text {inTiAl }} \text { at } \%\right]^{3}$

Thus, if the product of the activity in the melt is less than $K$, reaction (4) can proceed in the forward direction and $\mathrm{Y}_{2} \mathrm{O}_{3}$ can dissolve in the melt. Furthermore, whether reaction (4) is feasible or not would depend on the solubility of yttrium and oxygen in the melt and the kinetics of such dissolutions. Because the solubility of these elements is a function of temperature and holding time, the extent of the dissolution reaction and the consequent alloy contamination with yttrium and oxygen depend on the activity of the melt, which is greatly influenced by the contact of the oxide with the alloy. After the dissolution, yttrium and oxygen flow into melt by enrichment gradient. At the same time, a contamination layer is formed by the flowing of elements dissolved from the coatings, which is clearly developed in Fig.1, 3 and 4. The presence of electromagnetic stirring in the melt and the high diffusion rates of the solutes in the liquid state ensure a uniform distribution of the contamination in the molten alloy. In the solidification process, the elements in the melt are the convection and re-distribution at the pasty zone before the solidification line, which directly influence the microhardness seen in Fig.5.

In addition, the existence of small inclusions in the melt (Fig.1) suggests that besides dissolution, an erosion phenomenon might occur between the coating and the melt. Oxygen increases in the diffusion process regardless of the coating material used. According to the Ti-Al binary diagram, the segregation interaction would have occurred. As remarked, oxygen is the $\alpha$-stable element, which is easily reacted with $\mathrm{Al}, \mathrm{Y}, \mathrm{Zr}$, etc. and leads to precipitation of oxides ${ }^{[18]}$. Additionally, Mcdeavitt S M also pointed out that oxygen has a smaller radius and can easily diffuse from the sample surface to the inside of the melt, which makes oxygen a key element in the study of the interaction between the TiAl alloy and the crucible ${ }^{[19]}$. Besides, oxygen enrichment is not stable but up and down around boundary, as can be also seen in Fig.4. The location between the interface and the sample surface where the oxygen enrichment decreases extensively can be distinguished by the thickness of interaction layer. The larger the oxygen concentration gradient is, the longer the distance the oxygen diffuses, which can be indirectly presented in Fig.1.

In summary, the interaction between the oxides and the molten TiAl alloy include both chemical dissolution and erosion depending on the interfacial reaction. Furthermore, there is a possibility that aluminum is oxidized and forms a solid solution body due to the large activity of aluminum in the molten alloy. Another possible explanation for the existence of oxide particles dispersed in the metal matrix could be the re-precipitation which occurs during solidification, due to the reduction in the solubility of dissolute elements from the coatings. Moreover, particles which are dissolvable in the melt with low concentration of elements from the interface dissolve and precipitate from the melt with high concentration of the elements during solidification, and the precipitated particles flow in the direction of the crystal. When the melt reaches the liquid state and its fluidity is high enough, it can easily penetrate the interstices. As a result, the rate of the coating erosion is increased and the alloy gets contaminated. These findings suggest that the porosity of the coating should be decreased and the erosion resistance should be improved. But a reduction in the thermal shock resistance of the coating could be produced by the low porosity. Accordingly then, it is important to keep a balance between the thermal shock resistance and the porosity of the coating to reduce the erosion effect and the alloy contamination to a minimum level.

\section{Conclusions}

1) Varying degrees of interfacial reactions occurs between the DS Ti-48Al alloy and the aluminum mold with 
different protective coatings. The $\mathrm{Y}_{2} \mathrm{O}_{3}$ protective coating exhibits an effective barrier capability to avoid direct contact between the mold base material and the TiAl melt with the slightest reaction layer of $12 \mu \mathrm{m}$.

2) The extent of dissolution and consequent alloy contamination with $\mathrm{Ti}, \mathrm{Al}, \mathrm{O}$, etc. depends on both the solubility and stability of the coating materials. Although the $\mathrm{Y}_{2} \mathrm{O}_{3}$ coating is found to undergo some erosion and is slightly dissolved by the molten TiAl due to the coating-metal interactions, high quality TiAl castings manufactured with the $\mathrm{Y}_{2} \mathrm{O}_{3}$ coating are obtained.

3) The diffusion of elements, especially $\mathrm{O}$, can be seen as an important factor in the control of the interface reaction process. The whole reaction process consists of the stages of shedding dissolution, diffusion, precipitation of solid solution, and the generation of the matrix inclusions mainly due to active atomic dissolution, long-range diffusion from the coating and the enrichment in the substrate.

\section{References}

1 Zhang Huarui, Gao Ming, Tang Xiaoxia. Acta Metallurgica Sinica $[\mathrm{J}], 2010,46(7): 890$

2 Imayev V, Oleneva T, Imayev R et al. Intermetallics [J], 2012, 26: 91

3 Zhao Ertuan, Kong Fantao, Chen Yuyong et al. Trans Nonferrous Met Soc China[J], 2011, 21(2): 348

4 Ma F C, Lu W J, Qin J N et al. Materials Science and Engineering A[J], 2006, 416(1-2): 59
5 Harding R A. Kovove Mater[J], 2004, 42: 225

6 Shouren W, Peiquan G, Liying Y et al. J Mater Process Technol [J], 2008, 204: 492

7 Tetsui T. Mater Sci Forum[J], 2007, 361-363: 379

8 Virieux X Y, Desmaison J, Labbe J C et al. Materials Science [J], 1997: 925

9 Koltsov A., Hodaj F., Eustathopoulos N. Journal of the European Ceramic Society[J], 2009, 29: 145

10 Fu Binguo, Wang Hongwei, Zou Chunming et al. Trans Nonferrous Met Soc China[J], 2014, 24: 3118

11 Chen Yanfei, Xiao Shulong, Tian Jing et al. Trans Nonferrous Met Soc China[J], 2011, 21: 342

12 Kostov A, Friedrich B. Comput Mater Sci[J], 2006, 38: 374

13 Luo Wenzhong, Shen Jun, Min Zhixian et al. Rare Metal Materials and Engineering [J], 2009, 38(8):1441 (in Chinese)

14 Luo Wenzhong, Shen Jun, Li Qinglin et al. Acta Metallurgica Sinica[J], 2007, 43(12): 1287 (in Chinese)

15 Cui Renjie, Tang Xiaoxia, Gao Ming et al. Trans Nonferrous Met Soc China[J], 2012, 22: 887

16 Li Bangsheng, Liu Aihui, Nan Hai et al. Trans Nonferrous Met Soc China[J], 2008, 18: 518

17 Cancarevic M, Zinkevich M, Aldinger F. Calphad[J], 2007, 31: 330

18 Chen Ruirun, Ding Hongsheng, Yang Jieren et al. Trans Nonferrous Met Soc China[J], 2012, 22: 647

19 Mcdeavitt S M, Billings G W, Indacochea J E. Journal of Materials Engineering and Performance [J], 2002, 11: 392

\title{
定向凝固 Ti-48Al 合金与不同氧化物铸型涂层界面反应的研究
}

隋艳伟，冯 坤，程 成，戚继球，何业增，委福祥，孟庆坤，孙 智，沈承金

(中国矿业大学, 江苏 徐州 221116)

\begin{abstract}
摘 要: 研究了定向凝固过程中 $\mathrm{Ti} 48 \mathrm{Al} 7 \mathrm{Nb} 2.5 \mathrm{~V} 1 \mathrm{Cr}$ 合金分别与 $\mathrm{Al}_{2} \mathrm{O}_{3} 、 \mathrm{Y}_{2} \mathrm{O}_{3} 、 \mathrm{ZrO}_{2}$ 铸型涂层的界面反应。通过 SEM、EDS 以及 XRD 等检测方法对合金与铸型涂层的界面反应的微观组织、元素分布以及界面的相组成等进行表征; 同时结合对界面的硬度测量, 得到界 面反应层厚度。结果表明，合金熔体与不同铸型涂层均发生了界面反应。铸型涂层材料不同，界面反应剧烈程度也不同。反应过程中 在熔体和扩散元素的冲击下, 物理侵蚀和化学反应同时存在形成了反应层, 反应的强弱则与涂层材料有关。更值得注意的是，对钛铝 合金与铸型涂层的热力学性质进行了计算。研究还表明, 熔体在界面处的反应层主要由涂层材料的脱落扩散程度控制, 涂层中的元素 尤其是 $\mathrm{O}$ 元素的扩散是控制界面反应进程的重要因素。
\end{abstract}

关键词: 定向凝固; 界面反应; TiAl 合金; 铸型涂层

作者简介：隋艳伟, 男, 1981 年生, 博士, 副教授, 中国矿业大学材料学院, 江苏 徐州 221116, E-mail: 15852187006@163.com 